\title{
Clinical Spectrum of Primary Polycythaemia and Its Complications - Experience from a Single Center in Karnataka
}

\author{
Meera V.1 , Smitha R. ${ }^{2}$ \\ ${ }^{1}$ Department of Clinical Haematology, Bangalore Medical College and Research Institute, Bangalore, Karnataka, India. \\ ${ }^{2}$ Department of Clinical Haematology, Bangalore Medical College and Research Institute, Bangalore, Karnataka, India.
}

\section{ABSTRACT}

\section{BACKGROUND}

Awareness and diagnosis of Philadelphia Negative Chronic Myeloproliferative Disorders has now improved and there is a need for more epidemiological data from India.

\section{METHODS}

This is a retrospective study of patients of polycythaemia conducted at clinical haematology services, BMCRI, Bengaluru from 2010 to 2017.

\section{RESULTS}

88 patients of polycythaemia were retrospectively studied. $84.1 \%$ were male and $15.9 \%$ were female. Their ages ranged from 19 to 79 years. 75 (85.23\%) had Polycythaemia Rubra Vera (PRV). JAK-2 (V617F) mutation was positive in 33.33\%. The commonest presentation was with unexplained erythrocytosis in 50 (66.66\%), thrombosis in $20(26.66 \%)$ and with bleeding in 2 (2.66\%). 22 thrombotic events occurred in 20 PRV patients. Cortical sinus thrombosis was seen in $27.3 \%$, cerebrovascular accidents in $22.8 \%$, portal vein thrombosis in $13.6 \%$, pulmonary embolism in $9.1 \%$, central retinal artery occlusion in $13.6 \%$, myocardial infarction in $4.5 \%$ and digital infarction in $9.1 \%$ patients. 3 cases of PRV presented with diplopia. No other definitive cause for ocular palsy could be found. The JAK 2 positive group was slightly older than the negative group and had higher frequency of splenomegaly $(\mathrm{p}<0.05)$ and higher values for haemoglobin $(\mathrm{p}<0.001)$ and neutrophil counts $(\mathrm{p}<0.001)$ and platelet counts $(\mathrm{p}<0.05)$.

\section{CONCLUSIONS}

Patients with thrombosis, erythrocytosis, thrombocytosis and haemorrhage should be suspected to have myeloproliferative disorders like PRV and investigated. Ophthalmoplegia is a rare presentation and should raise the suspicion for polycythaemia. There is a higher probability of splenomegaly and higher values for haemoglobin and neutrophil counts and platelet counts in JAK 2 positive group.

\section{KEY WORDS}

Polycythaemia Rubra Vera (PRV), Philadelphia Negative Chronic Myeloproliferative Disorders, Ph-Negative CMPD / MPN, JAK-2 Mutation, Ophthalmoplegia, Thrombosis

\author{
Corresponding Author: \\ Dr. Meera $V$, \\ Department of Clinical Haematology, \\ Bangalore Medical College and Research \\ Institute, Fort, K. R. Road, Bangalore-2, \\ Karnataka, India. \\ E-mail: meerachakra@yahoo.com
}

DOI: $10.14260 /$ jemds/2020/535

How to Cite This Article:

Meera $V$, Smitha $R$. Clinical spectrum of primary polycythaemia and its complications - experience from a single center in Karnataka. J. Evolution Med. Dent. Sci. 2020;9(34):2461-2465, DOI: $10.14260 /$ jemds/2020/535

Submission 14-10-2019,

Peer Review 19-05-2020,

Acceptance 26-05-2020,

Published 24-08-2020.

Copyright (C) 2020 JEMDS. This is an open access article distributed under Creative Commons Attribution License [Attribution 4.0 International (CC BY 4.0)] 


\section{BACKGROUND}

Abnormal proliferation of all hematopoietic bone marrow elements and an absolute increase in red cell mass is characteristic of Polycythaemia Vera ${ }^{1-4}$. It should be suspected when men present with a haemoglobin $(\mathrm{Hb})$ greater than 18.5 $\mathrm{g} / \mathrm{dL}$ and in women with a Hb greater than $16.5 \mathrm{~g} / \mathrm{dL}$.

JAK2 mutation is now a major diagnostic and clonal marker for Ph-negative CMPD in the revised WHO classification and important in designing personalized treatments in coming times, 1,2 The abnormal proliferation in $\mathrm{PV}$ is due to constitutive activation of the JAK-STAT pathway and majority have the V617F mutation ${ }^{5,6,7}$ Discovery of nonreceptor tyrosine kinase JAK2 mutations (exon 14, JAK2 V617F and exon 12) in 2005,5-15 has furthered our understanding of the molecular mechanisms of Ph-ve CMPD such as PV, essential thrombocythemia (ET) and primary myelofibrosis (PMF) patients. Incidence of JAK2 V617F mutation reported has varied from $65-97 \%$ for PV, $23-57 \%$ for ET and 35-57\% for idiopathic myelofibrosis (IMF). ${ }^{5-15}$

JAK2 V617F mutation is a G-C to T-A transversion, leading to valine to phenylalanine substitution at codon 617 . This is a gain of function mutation causing the release of autoinhibitory action of JH2 and recruits STAT (Signal Transducer and Activator of Transcription) in the complete absence or in presence of only trace quantities of hematopoietic growth factors. This in turn leads to activation of a number of downstream pathways like JAK/STAT, PI3K/AKT and MAPK/ ERK.6-15

Secondary causes of polycythaemia must be ruled out. EPO overproduction occurs in hypoxia, tumours (e.g., kidney, brain, hepatoma, uterine fibroid, and pheochromocytoma), renal artery stenosis, and renal cysts. Other causes include androgen therapy, congenital erythrocytosis, EPO receptor hypersensitivity, auto-transfusion (blood doping), and selfinjection of EPO. Familial PV has been associated with mutations of the EPO receptor, high oxygen affinity haemoglobins and 2, 3-BPG deficiency.

Ph-negative CMPDs are being more often diagnosed, probably because more asymptomatic patients are diagnosed as a result of an increase in knowledge and more vigilant screening. There are only a few studies on the epidemiology of polycythaemia from India; this study provides insight on the presentations of polycythaemia patients in this part of the country and the incidence of JAK 2 (V617F) mutation in our PRV patients.

\section{METHODS}

This was a retrospective study of patients of polycythaemia referred to Clinical Haematology OPD from February 2010 to September 2017 at Victoria Hospital, BMCRI, Bangalore. The study was approved by Institutional Ethics Committee and informed consent was obtained.

Complete blood count with peripheral smear, liver function test, renal function test, arterial blood gas analysis, chest X-ray, abdominal ultrasound, and serum erythropoietin (EPO) levels were done in all patients for diagnosis. Bone marrow study and JAK 2 (V617F) mutation analysis, by PCR and gel electrophoresis in the peripheral blood leucocytes, was done at diagnosis in all PRV patients. Relevant tests such as Renal Doppler, abdominal computed tomography (CT) scan, intravenous pyelogram, pulmonary function tests, endocrine evaluation to look for secondary causes of polycythaemia were done as required.

For diagnosis of thrombosis, ultrasound with Doppler and/or MRI was done. CT scans and MRI (Magnetic Resonance Imaging) venography of the brain were done in all 3 patients of PRV with ophthalmoplegia. Extensive investigations were done in all patients with thrombotic events and ophthalmoplegia to exclude other identifiable explanations like trauma, infection, screening for hypertension, inflammatory causes, autoimmune risks with autoantibody profile and antiphospholipid antibodies, serum homocysteine levels, lipid profile and fasting and post prandial blood sugar levels. Those with concomitant risk factors were excluded from this data.

Polycythaemia vera was diagnosed as per revised WHO Criteria 201616

Major Criteria

1. $\mathrm{Hb}>16.5 \mathrm{gm} / \mathrm{dL}$ or $\mathrm{HCT}>49 \%$ (in males) $\& \mathrm{Hb}>$ $16 \mathrm{gm} / \mathrm{dL}$ or HCT $>48 \%$ (females).

2. Hyper cellular Bone marrow biopsy (for age) with trilinear proliferation.

3. Positive report for JAK2V617F or JAK 2 exon 12 mutation.

\section{Minor Criterion}

1. Subnormal Erythropoietin (EPO) levels.

Diagnosis is confirmed if all the 3 major criteria are met or 2 major and minor criteria is positive. Bone marrow biopsy is not required in patients with sustained absolute erythrocytosis $\mathrm{Hb}>18.5 \mathrm{gm} / \mathrm{dL}$ or $\mathrm{HCT}>55.5 \%$ (males), $\mathrm{Hb}>$ $16.5 \mathrm{gm} / \mathrm{dL}$ or HCT $>49.5 \%$ (females), if maturation criteria is present) Secondary polycythaemia was diagnosed as $\mathrm{Hb}>16.5$ $\mathrm{gm} / \mathrm{dL}$ or HCT $>49 \%(\mathrm{~m})$ and $\mathrm{Hb}>16 \mathrm{gm} / \mathrm{dL}$ or HCT $>48 \%$ (f) with presence of secondary underlying causes and not fitting into the diagnostic criteria for Vera.

\section{Statistical Analysis}

Statistical analysis was done using SPSS software. Quantitative data was expressed as mean \pm standard deviation (SD) and compared using student $t$ test. $P$ value $<0.05$ was considered significant. Categorical data was expressed as percentages and compared using chi square test. MS word and excel were used to generate tables and graphs.

\section{RESULTS}

88 patients of polycythaemia were retrospectively studied, 74 $(84.1 \%)$ of them were male and $14(15.9 \%)$ were female. Male to female ratio was $4: 1$. Age of patients ranged from 19 to 79 years. Mean age was $45.16 \pm 14.22$ years. 75 (85.23\%) of the patients were found to have PRV. Among them 60 (80\%) were male and 15 (20\%) female. Serum EPO levels were low in 35 (46.66\%) patients of PRV. JAK-2 (V617F) mutation was positive in 25 (33.33\%). The mean age of patients who were 
positive for JAK-2 mutation was $47.76 \pm 12.64$ years. Secondary polycythaemia was diagnosed in 13 (14.77\%), among whom 12 were male and 1 female.

\begin{tabular}{|cccc|}
\hline Our Study & JAK-2 Positive & JAK-2 Negative & P Value \\
Hb (gm/dL) & $20.79 \pm 1$ & $19.64 \pm 1$ & $<0.001$ \\
WBC (Thousand) per $\left.\mathrm{mm}^{3}\right)$ & $11.79 \pm 3.27$ & $7.28 \pm 1.8$ & $<0.001$ \\
Platelet count $\left(\mathrm{lakhs} / \mathrm{mm}^{3}\right)$ & $4.96 \pm 2$ & $3.80 \pm 0.94$ & $<0.05$ \\
Splenomegaly & $15 / 25(60 \%)$ & $15 / 50(30 \%)$ & $<0.05$ \\
\hline Table 1. Clinico-Haematological Parameters of & \\
JAK-2 Positive and Negative Patient Groups & \\
\hline
\end{tabular}

\begin{tabular}{|c|c|c|c|}
\hline & $\begin{array}{l}\text { Our } \\
\text { Study }\end{array}$ & $\begin{array}{l}\text { Cecil } \\
\text { Ross } \\
\text { et al }\end{array}$ & $\begin{array}{c}\text { Sudha } \\
\text { Sazawal } \\
\text { et al }\end{array}$ \\
\hline No. of cases & 75 & $\begin{array}{c}\text { Entire MPD-39 } \\
\text { PRV-14+8 }\end{array}$ & 34 \\
\hline Age & $45.16 \pm 14.22$ & $55.5 \pm 14.5$ & $52 \pm 14.3$ \\
\hline Sex M/F & $60 / 15$ & $27 / 12$ & $26 / 8$ \\
\hline Thrombosis & 22 events & 14 & 1 \\
\hline Haemorrhage & 2 & - & 3 \\
\hline $\mathrm{Hb}(\mathrm{gm} / \mathrm{dL})$ & $19.9 \pm 1.06$ & $18 \pm 1.8$ & $17.3 \pm 2.92$ \\
\hline WBC (Thousand per $\mathrm{mm}^{3}$ ) & $8608.10 \pm 3136.38$ & $9.6 \pm 2.6$ & 29.9 \\
\hline Platelet count (lakhs $/ \mathrm{mm}^{3}$ ) & $4.14 \pm 1.45$ & $4.7 \pm 2.2$ & 3.68 \\
\hline \multicolumn{4}{|c|}{ Table 2. Comparison with Literature } \\
\hline
\end{tabular}
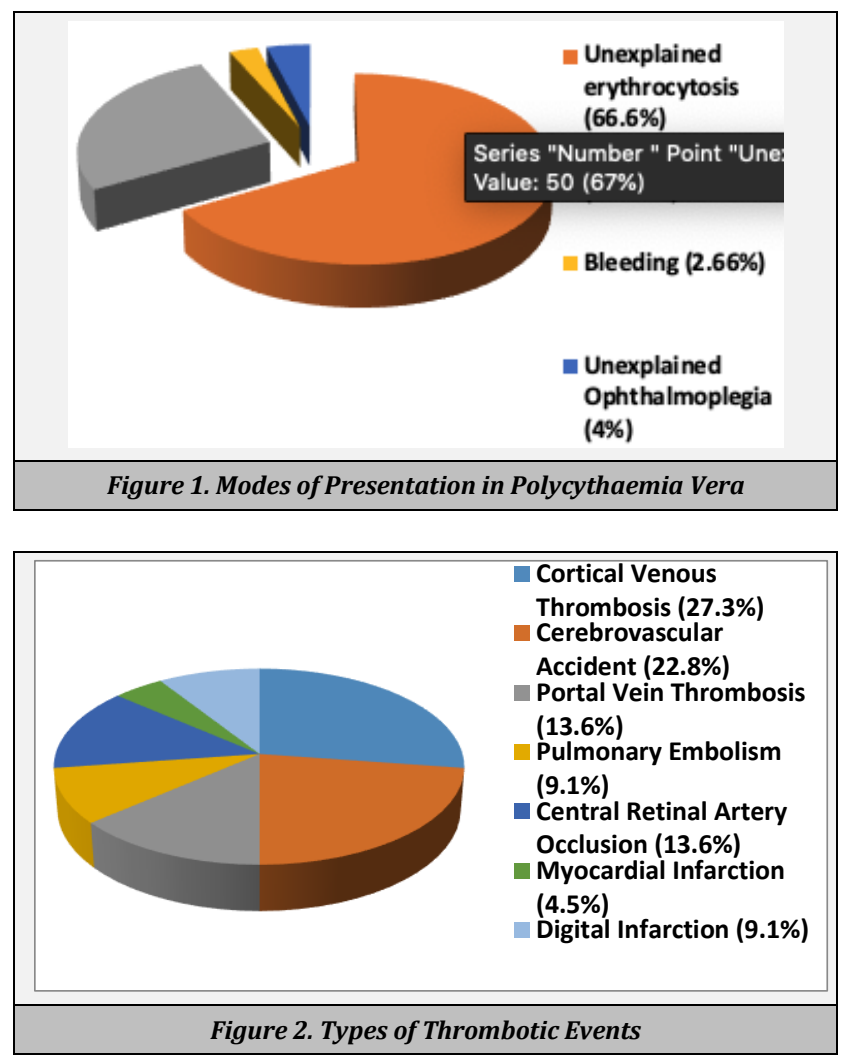

72(96\%) of the PRV patients had conjunctival plethora and ruddy cyanosis. Splenomegaly was seen in $30(40 \%)$ of whom $60 \%$ of them were JAK-2 mutation positive. 15/25 (60\%) patients were JAK-2 mutation positive and 15/50 (30\%) patients were JAK-2 mutation negative.

The commonest presentation among patients of PRV was with unexplained erythrocytosis in 50 (66.66\%) and thrombosis was seen in $20(26.66 \%)$ and bleeding in 2 $(2.66 \%)$. Both the patients with bleeding had thrombocytosis (platelet counts were $10 \mathrm{~L} / \mathrm{mm}^{3}$ and $8.6 \mathrm{~L} / \mathrm{mm}^{3}$ respectively), were females and JAK-2 mutation positive. (Figure 1)

Twenty-two (22) thrombotic events occurred in the 20 PRV patients. Cortical sinus thrombosis was seen in 6 (27.3\%), cerebrovascular accidents in $5(22.8 \%)$, portal vein thrombosis in $3(13.6 \%)$, pulmonary embolism in $2(9.1 \%)$, central retinal artery occlusion in $3(13.6 \%)$, myocardial infarction in 1 (4.5\%) and digital infarction in 2 (9.1\%) patients. (Figure 2)

Three (4\%) cases of PRV presented with diplopia. On examination two patients had restriction of lateral gaze, while one had restriction of down gaze on adduction, pointing towards $6^{\text {th }}$ nerve and $4^{\text {th }}$ nerve palsies respectively. Hb levels were $>18$ in all three cases and PCV> 45. CT and MRI venography of the brain revealed no abnormalities. LP-CSF was normal. ANA and ANCA were negative. Serum erythropoietin was reduced in one, normal in the other two. JAK2 mutation was positive in two patients. Platelet count was elevated in all 3. Definitive cause of ocular palsies could not be found out in all our 3 cases. Patients were started on, aspirin, hydroxyurea, short term steroids and underwent phlebotomies to which there was complete response.

The mean $\mathrm{Hb}$ was $19.9 \pm 1.06 \mathrm{gm} / \mathrm{dL}$ and the Mean TLC was $8608.10 \pm 3136.38 / \mathrm{mm}^{3}$ and the mean platelet count was $4.14 \pm 1.45 \mathrm{lakh} / \mathrm{mm}^{3}$. The mean $\mathrm{Hb}$ of the JAK-2 mutation positive PRV patients was $20.79 \pm 1 \mathrm{gm} / \mathrm{dL}$. Their Mean TLC of was $11,794.11 \pm 3271.89 / \mathrm{mm}^{3}$ and the mean platelet count was $4.96 \pm 2 \mathrm{lakh} / \mathrm{mm}^{3}$. The mean $\mathrm{Hb}$ of the JAK-2 mutation negative PRV group was $19.64 \pm 1 \mathrm{gm} / \mathrm{dL}$. Their Mean WBC count was $7287 \pm 1876.9 / \mathrm{mm}^{3}$ and the mean platelet count was $3.8 \pm 0.9 \mathrm{lakh} / \mathrm{mm}^{3}$. Follow up during $4.8 \mathrm{yrs}$. showed that 2 patients had transformed to myelofibrosis.

\section{DISCUSSION}

PRV is a clonal disorder of the pluripotent stem cell which can differentiate into red blood cells, granulocytes, and platelets. There is erythropoietin (Epo) -independent in vitro erythroid colony formation. Homozygous JAK2 mutation causing pronounced kinase activity leads to trilinear megakaryocyte, erythroid, and granulocytic myeloproliferation, myeloid metaplasia, and is associated with 'Classical PV' complicated by thrombotic events and platelet-mediated microvascular thrombotic syndrome of thrombocythemia. ${ }^{17-24}$ The hypersensitive platelets produced by spontaneously proliferating enlarged megakaryocytes in the bone marrow of ET and PV patients spontaneously activate and secrete their products, forming aggregates that transiently plug the microcirculation, or result in occlusive platelet thrombi in arterioles or small arteries leading to transient ischemic attacks and thrombotic complications respectively. ${ }^{19-24}$ Acquired Von Willebrand disease associated with extreme thrombocytosis is the major cause for bleeding.

Serum EPO levels should be low to normal in patients with PRV but high in patients with secondary polycythaemia, although there may be some overlap. Presence of JAK2 V617F mutation along with a low EPO level favours the diagnosis of PRV. When JAK2V617F mutation test is negative but the EPO level is low, testing for other mutations of JAK2 identifies a minority of patients with PRV. All the other patients having a normal or elevated EPO level should be evaluated for secondary polycythaemia. Arterial oxygen saturations of less than $92 \%$ points towards secondary polycythaemia. 
Males were more affected than females. The mean age of our patients was lower than other studies ${ }^{25,26}$ (Table 2). $26.66 \%$ of the patients presented with thrombosis and investigations revealed polycythaemia. Hence basic investigation for an underlying aetiology should be done in all patients with thrombotic events, irrespective of their age and other risk factors like hypertension, which can also occur due to erythrocytosis. There was a higher probability of splenomegaly $(\mathrm{p}<0.05)$ and higher values for haemoglobin $(p<0.001)$ and neutrophil counts $(p<0.001)$ and platelet counts $(\mathrm{p}<0.05)$ in JAK 2 positive group similar to other studies $^{25,26}$. (Table 1)

Treatment for PV should be risk-adapted ${ }^{3,4}$. Patients are stratified into low-risk and high-risk categories based on age (if more than 60 years) and previous history of thrombosis. Patients who are younger than 60 years with no history of thrombosis with platelet count below $1,500 \times 10^{9} / \mathrm{L}$, and the absence of cardiovascular risk factors like smoking, hypertension, congestive heart failure are considered low risk. They are treated with phlebotomy alone. High-risk patients require phlebotomy plus cytoreductive therapy or interferon. Hydroxyurea is used as first-line therapy. Aspirin as well as cytoreductive therapy is needed to control thrombocytosis, leucocytosis and extra medullary haematopoiesis. Interferon is safe and recommended in women of childbearing age and in patients who cannot tolerate hydroxyurea.

The goal of therapy is a haematocrit of $45 \%$ for men and $42 \%$ for women and is associated with a four-fold decrease of major cardiovascular events and prevention of thrombotic complications but does not prevent the microvascular circulation disturbances and occlusive thrombotic complications because thrombocythaemia persists. Aspirin induces irreversible inhibition of platelet cyclo-oxygenase (COX-1) activity and aggregation, thereby relieving the peripheral, cerebral and ocular ischemic disturbances 19.20,21,22.

JAK2 inhibitors are being evaluated in clinical trials for PV; however, the initial enthusiasm hoping these drugs could selectively target mutant cells and cause a molecular remission similar to Imatinib in CML (Chronic Myeloid Leukemia) has proved unreal.

\section{CONCLUSIONS}

Patients with thrombosis, erythrocytosis, thrombocytosis and haemorrhage should be suspected to have myeloproliferative disorders like PRV and investigated. Ophthalmoplegia is a rare presentation and should raise the suspicion for polycythaemia. There is a higher probability of splenomegaly and higher values for haemoglobin and neutrophil counts and platelet counts in JAK 2 positive group.

JAK2 mutation analysis should be a part of initial evaluation of patients suspected with BCR-ABL negative CMPD. Other known JAK2 mutations like exon 12-15, MPN and CALR also should be evaluated, which was not available to us at that point of time. JAK2 mutation analysis can be useful in situations like unusual and/or extensive thrombotic complications like cortical sinus thrombosis, abdominal thrombotic events, as a surrogate marker to diagnose CMPDs.
Financial or Other Competing Interests: None.

\section{REFERENCES}

[1] Tefferi A, Vardiman JW. Classification and diagnosis of myeloproliferative neoplasms: the 2008 World Health Organization criteria and point-of-care diagnostic alogirthms. Leukemia 2008;22(1):14-22.

[2] Vardiman JW, Harris NL, Brunning RD. The World Health Organization (WHO) classification of the myeloid neoplasms. Blood 2002;100(7):2292-302.

[3] Vannucchi AM, Guglielmelli P, Tefferi A. Advances in understanding and management of myeloproliferative neoplasms. CA Cancer J Clin 2009;59(3):171-91.

[4] McMullin MF, Bareford D, Campbell P, et al. Guidelines for the diagnosis, investigation and management of polycythemia/erythrocytosis. $\mathrm{Br} \quad \mathrm{J}$ Haematol 2005;130(2):174-95.

[5] Levine RL, Wadleigh M, Cools J, et al. Activating mutation in the tyrosine kinase $\mathrm{JAK}_{2}$ in polycythemia vera, essential thrombocythemia, and myeloid metaplasia with myelofibrosis. Cancer Cell 2005;7(4):387-97.

[6] James C, Ugo V, Le Couedic JP, et al. A unique clonal JAK mutation leading to constitutive signalling causes polycythemia Vera. Nature 2005;434(7037):1144-8.

[7] Kralovics R, Passamonti F, Buser AS, et al. A gain-offunction mutation of $\mathrm{JAK}_{2}$ in myeloproliferative disorders. N Engl J Med 2005;352(17):1779-90.

[8] Baxter EJ, Scott LM, Campbell PJ, et al. Acquired mutation of the tyrosine kinase $\mathrm{JAK}_{2}$ in human myeloproliferative disorders. Lancet 2005;365(9464):1054-61.

[9] Levine RL, Pardanani A, Tefferi A, et al. Role of $\mathrm{JAK}_{2}$ in the pathogenesis and therapy of myeloproliferative disorders. Nat Rev Cancer 2007;7(9):673-83.

[10] Spivak JL, Barosi G, Tognoni G, et al. Chronic myeloproliferative disorders. Hematology Am Soc Hematol Educ Program 2003;200-24.

[11] Kaushansky K. On the molecular origins of the chronic myeloproliferative disorders: it all makes sense. Hematology Am Soc Hematol Educ Program 2005:533-7.

[12] Goldman JM. A unifying mutation in chronic myeloproliferative disorders. $\mathrm{N}$ Engl J Med 2005;352(17):1744-6.

[13] James C, Ugo V, LeCouedic JP, et al. A unique clonal JAK 2 mutation leading to constitutive signaling causes polycythemia Vera. Nature 2005;434:1144-8.

[14] Scott LM, Tong W, Levine RL, et al. JAK2 exon 12 mutations in polycythemia vera and idiopathic erythrocytosis. $\mathrm{N}$ Engl J Med 2007;356(5):459-68.

[15] Pikman Y, Lee BH, Mercher T, et al. MPLW515L is a novel somatic activating mutation in myelofibrosis with myeloid metaplasia. PLoS Med 2006;3(7):e270.

[16] Maffioli M, Mora B, Passamonti F. Polycythemia vera: from new, modified diagnostic criteria to new therapeutic approaches. Clinical Advances in Hematology \& Oncology 2017;15(9):700-7.

[17] Carobbio A, Finazzi G, Guerini V, et al. Leukocytosis is a risk factor for thrombosis in essential thrombocythemia: 
interaction with treatment, standard risk factors and Jak 2 mutation status. Blood 2007;109(6):2310-3.

[18] Finazzi G, Rambaldi A, Guerini V, et al. Risk of thrombosis in patients with essential thrombocythemia and polycythemia vera according to $J A K_{2} \quad \mathrm{~V}_{17} \mathrm{~F}$ mutation status. Haematologica 2007;92(1):135-6.

[19] Koudstaal PJ, Koudstaal A. Neurologic and visual symptoms in essential thrombocythemia: efficacy of lowdose aspirin. Semin Thromb Hemost 1997;23(4):365-70.

[20] Michiels JJ, Koudstaal PJ, Mulder AH, et al. Transient neurologic and ocular manifestations in primary thrombocythemia. Neurology 1993;43(6):1107-10.

[21] Michiels JJ. Platelet-mediated microvascular inflammation and thrombosis in thrombocythemia vera: a distinct aspirin-responsive arterial thrombophilia, which transforms into a bleeding diathesis at increasing platelet counts. Pathol Biol (Paris) 2003;51(3):167-75.

[22] Pearson TC. Hemorheologic considerations in the pathogenesis of vascular occlusive events in polycythemia vera. Semin Thromb Hemost 1997;23(5):433-9.

[23] Hoyt CS. Acquired double elevator palsy and polycythaemia vera. J Pediatr Ophthalmol Strabismus 1978;15(6):362-5.

[24] Michiels JJ, Berneman Z, Bockstaele DV, et al. Clinical and laboratory features, pathobiology of platelet-mediated thrombosis and bleeding complications and the molecular etiology of essential thrombocythemia and polycythemia vera: therapeutic implications. Semin Thromb Hemost 2006;32(3):174-207.

[25] Ross C, Navya CJ, Vanamala, et al. Polycythemia vera and essential thombocythemia - a single institution experience. Indian J Med \& Paediatric Oncology 2008;29(4):7-11.

[26] Sazawal S, Bajaj J, Chikkara S, et al. Prevalence of JAK2 V617F mutation in Indian patients with chronic myeloproliferative disorders. Indian $\mathrm{J}$ Med Res 2010;132:423-7. 